\title{
Control of Anisotropic Crystallographic Texture in Powder Bed Fusion Additive Manufacturing of Metals and Ceramics-A Review
}

\author{
KOJI HAGIHARA ${ }^{1,2,3}$ and TAKAYOSHI NAKANO (1) ${ }^{2,3,4}$ \\ 1.-Department of Physical Science and Engineering, Nagoya Institute of \\ Technology, Gokiso, Nagoya 466-8555, Japan. 2.-Division of Materials and Manufacturing \\ Science, Graduate School of Engineering, Osaka University, 2-1, Yamadaoka, Suita, Osaka 565- \\ 0871, Japan. 3.-Anisotropic Design and AM Research Center, Osaka University, \\ 2-1, Yamadaoka, Suita, Osaka 565-0871, Japan. 4.—e-mail: nakano@mat.eng.osaka-u.ac.jp
}

Additive manufacturing (AM) enables the production of complex, net-shape geometries. Additionally, in AM of metal and ceramics, which has received less attention, the microstructure and texture of the product can be arbitrarily controlled by selecting appropriate process parameters, thereby enabling unprecedented superior properties. This paper discusses recent progress pertaining to texture evolution mechanisms and control methods, with an emphasis on selective laser melting. One of the unique characteristics of AM is that the texture can be varied as a function of position within the product by controlling the scan strategy. The transient behavior of the texture and the factor used to control it via the scan strategy are discussed. In addition, the texture evolution behavior of face- and body-centered cubic as well as noncubic materials is discussed. The importance of the crystallographic "multiplicity" of the preferential crystal growth direction is described to understand the evolution behavior of the texture in such materials.

\section{INTRODUCTION}

Recently, additive manufacturing (AM) has attracted considerable attention for application in important manufacturing processes. ${ }^{1-6}$ The most significant advantage of AM is that it allows the production of complex, net-shape geometries ${ }^{7-10}$ that cannot be achieved using standard manufacturing techniques such as casting or forming. Hence, AM has been applied to fabricate various products, including those with a hollow structure, three-dimensional complex porousous bodies, and custom-developed products. Moreover, in some cases, AM has been combined with topology optimization. ${ }^{11,12}$

Another notable characteristic of metal AM, which has received less attention compared with shape control, is the wide control that is possible over microstructure and texture. ${ }^{13-41}$ In particular, texture control, i.e.,

(Received August 19, 2021; accepted October 1, 2021;

published online November 11, 2021) crystal orientation control, is one of the most important factors governing the properties of materials, in addition to their mechanical properties such as strength, ${ }^{42-}$ ${ }^{44}$ ductility, ${ }^{42-44}$ Young's modulus, ${ }^{45-47}$ and wear resistance, ${ }^{48}$ as well as other functional properties such as magnetism ${ }^{49}$ and corrosion resistance. ${ }^{50}$ Hence, precise crystal orientation control can result in unprecedented superior properties.

There are two strategies to control the texture: random polycrystallization to obtain isotropic properties, ${ }^{51-54}$ and the synthesis of single-crystalline or strongly texture-oriented material to obtain anisotropic properties. ${ }^{13-41}$ Powder bed fusion processing is widely used for metal AM. Two methods exist, using either a laser or electron beam as the heat source. These used to be called selective laser melting (SLM) and electron beam melting (EBM), but are currently called laser beam powder bed fusion (L-PBF) and electron beam powder bed fusion (EB-PBF), respectively. Regarding texture control, the formation of texture during AM has been reported for more than a decade, but its intentional 
control has not been sufficiently studied, particularly in EB-PBF. ${ }^{14-17}$ In contrast, strategies for the deliberate free control of texture in L-PBF has become a popular topic recently. Hence, the deliberate usage of texture to induce new, superior functionality in products has become popular in recent years. ${ }^{27,31,55,56}$ Its discussion is thus emphasized herein.

Texture development is assumed to be governed by the balance between the thermal gradient at the solid-liquid interface, the migration velocity of the solid-liquid interface, and the melt-pool shape. ${ }^{20,21,31,34}$ However, the detailed mechanisms, such as the variation in texture depending on the material, have not yet been clarified sufficiently. Herein, recent progress pertaining to the understanding of texture evolution mechanisms and control methods for L-PBF, primarily those applied in our group, is described. The combination of intentional control over texture as well as complicated, near-net shape enables the creation of a hierarchical structure in the product, thereby providing a new opportunity for inducing superior property control in novel manufacturing processes.

\section{VARIATIONS IN TEXTURE WITH L-PBF PROCESS PARAMETERS}

It is well known that the preferential growth direction of columnar cells during solidification of face-centered cubic (fcc) and body-centered cubic (bcc) metals is generally parallel to $<100>.^{57}$ Regarding the solidification process in the melt pool in powder-bed-fusion-type AM of metals, columnar cells tend to grow parallel to the heat-flow direction, which is almost perpendicular to the tangential direction of the melt-pool boundary, ${ }^{20,21,58}$ if the effect of epitaxial growth is negligible. Hence, the texture evolution characteristics in L-PBF can vary depending on the fabrication process parameters via their effect on the heat flow direction and the resulting change in the melt-pool shape.

It is generally known that the dimensional accuracy of products obtained by L-PBF is governed by the energy density $E$, expressed $a^{2}$

$$
E=\frac{P}{v \cdot d \cdot h}
$$

where $P, v, d$, and $h$ indicate the laser power, laser scanning speed, scan pitch, and accumulation thickness of the powder, respectively. A precisely shaped body with good dimensional accuracy can be obtained by selecting a suitable $E$-value for L-PBF. However, in products fabricated using the same $E$-value, the texture varies depending on the $P, v, d$, and $h$ values. Ishimoto et al. previously investigated this phenomenon in a bcc-structured Ti-15Mo-5Zr-3Al (wt.\%) alloy for application as an implant material. ${ }^{27,59-61}$ Herein, more precise results are presented. Five different Ti-15Mo-5Zr-3Al specimens were fabricated via L-PBF with a fixed $E$-value of 50
Table I. Laser conditions used to fabrication bccTi-15Mo-5Zr-3Al samples shown in Fig. 2.

\begin{tabular}{|c|c|c|c|c|c|}
\hline Specimen no. & 1 & 2 & 3 & 4 & 5 \\
\hline Laser power (W) & 75 & 150 & 225 & 300 & 360 \\
\hline Scan speed $(\mathrm{mm} / \mathrm{s})$ & 250 & 500 & 750 & 1000 & 1200 \\
\hline
\end{tabular}

The other parameters of scan pitch $(d)$ and accumulation thickness of the powder $(h)$ were fixed at $0.1 \mathrm{~mm}$ and $0.06 \mathrm{~mm}$ for all specimens.

$\mathrm{J} / \mathrm{mm}^{3}$ while $P$ and $v$ were varied systematically (Table I). The X-scan strategy was applied in this study, where the laser is scanned bidirectionally (zigzag) in one direction ( $x$-direction). In this study, the scanning and build direction were set parallel to the $x$ - and $z$-direction. A schematic illustration of the $\mathrm{X}$-scan strategy is shown in Fig. 1a.

In all five conditions, rectangular specimens with precise shape were successfully fabricated, but the textures that evolved in them differed significantly. Figure 2a, b, c, d and e shows crystal orientation maps taken by electron backscatter diffraction analysis in scanning electron microscopy (SEMEBSD) on the $y-z$ section, i.e., the plane perpendicular to the scanning $x$-direction. Figure $2 \mathrm{a}, \mathrm{b}, \mathrm{c}, \mathrm{d}$ and e correspond to fabrication condition $1-5$ in Table I, respectively. Below the orientation maps, the corresponding $\{100\}$ and $\{110\}$ pole figures are shown. Condition 5 shown in Fig. 2e corresponds to the significant texture evolution reported previously. ${ }^{27}$ The evolution of strong texture with $<001>$ aligned along the scanning $x$-direction and $<110>$ along the $y$-and $z$-directions is shown in Fig. 2e However, when the laser power or scanning speed was decreased, the degree of texture evolution gradually weakened. Under condition 5 , the growth of grains with the same orientation color along the building $z$-direction was significant beyond the melt-pool boundaries, suggesting epitaxial grain growth along the $z$-direction. In samples fabricated at a lower scanning speed, the elongation of grains with the same orientation color along the $z$-direction was observed; however, the crystal orientation in those grains showed a wide distribution other than red (i.e., <001>), resulting in weaker texture. Furthermore, under fabrication condition 1, the growth of grains along the $z$-direction itself was disturbed, resulting in the formation of almost random texture. To quantitatively evaluate the degree of alignment of the crystal orientation in the product, the $P$ value has been proposed. ${ }^{40}$ Along the $\langle u v w\rangle$ direction, it is defined as $\cos ^{2} \alpha_{<u v w>\text {, }}$, where $\alpha_{<u v w>}$ is the smallest angle between the observation direction and one of the equivalent orientations of $\langle u v w\rangle$. The maximum value of $P_{<u v w>}$ is 1 , and the closer it is to 1 , the stronger the crystal orientation alignment of $\langle u v w\rangle$ along the observation direction. 


\section{X-scan}

(a)

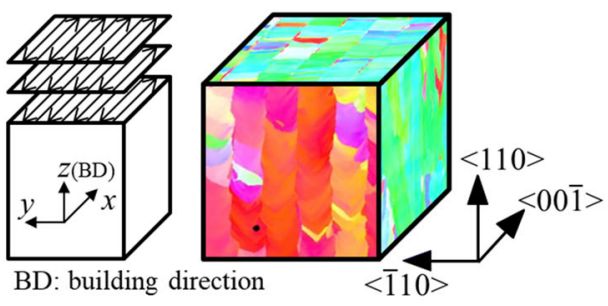

(c)

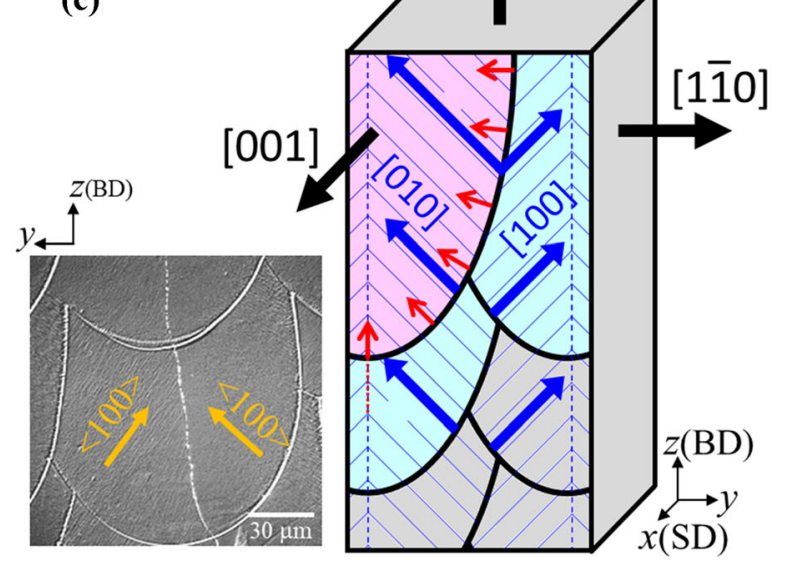

$\uparrow$ Maximum thermal gradient direction (b)

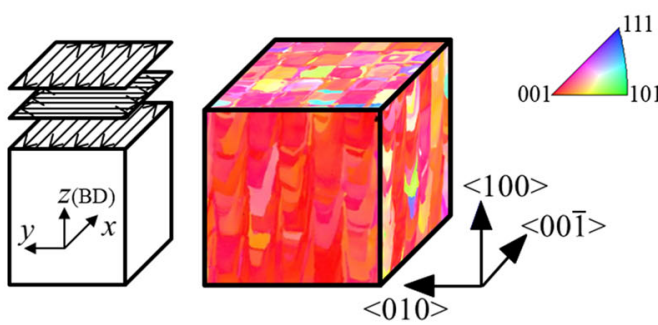

(d)

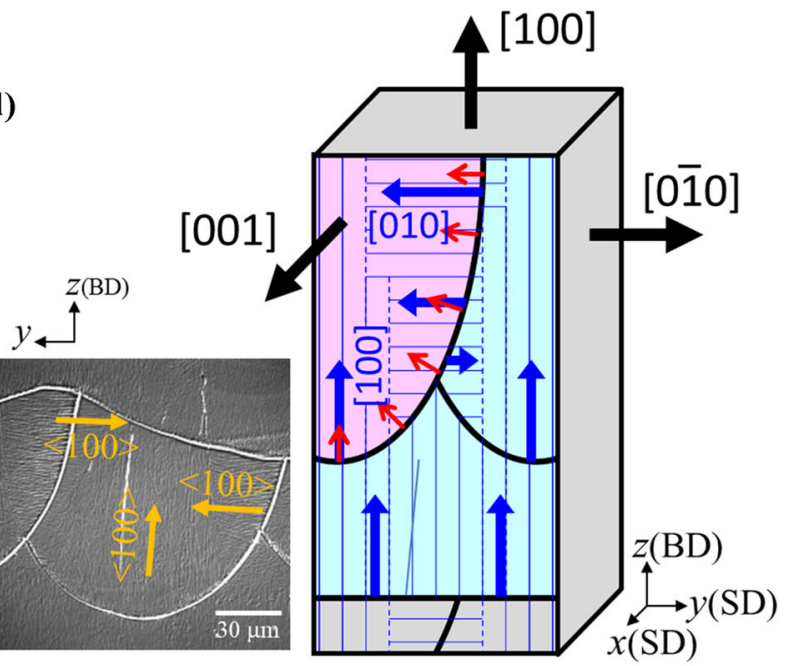

SD: scanning direction

\section{XY-scan}



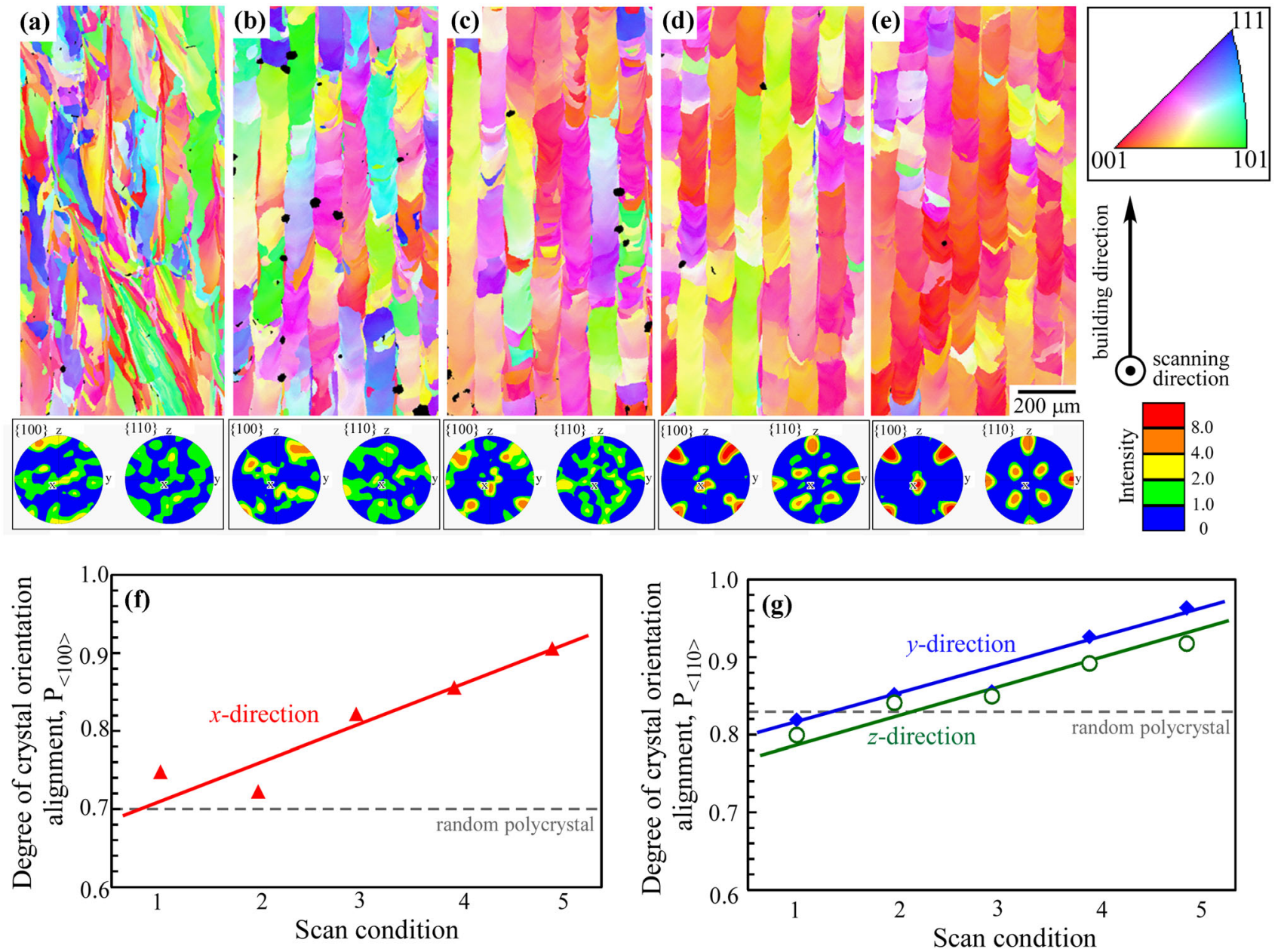

Fig. 2. (a-e) SEM-EBSD crystal orientation maps and corresponding $\{100\}$ and $\{110\}$ pole figures (below) showing texture variation based on laser power and scanning speed, measured on $y-z$ section perpendicular to the scanning $x$-direction, in Ti-15Mo-5Zr-3Al alloy specimens fabricated using the X-scan strategy. The L-PBF process parameters correspond to conditions 1-5 in Table I, respectively. (f, g) Variations in $P_{<001>}$ measured along the scanning $x$-direction, and $P_{<110>}$ measured along the $y$ - and $z$-directions versus fabrication process parameters. Some figures reprinted from Figs. 3-5 from Ref. 59 with permission from the Journal of Smart Processing.

alignment of $<001>$ along the $x$-direction, is one of the notable factors affecting the evolution of strong texture. The observations shown in Fig. 3 suggests that this can be accomplished by inducing two-dimensional growth of columnar cells, restricted to the $y-z$ section perpendicular to the scanning $x$-direction. This is discussed further in the next section.

\section{TEXTURE DEVELOPMENT MECHANISM IN FCC AND BCC MATERIALS}

Texture formation in powder-bed-fusion-type AM products has been reported for more than a decade, e.g., in the work by Al-Bermani et al. ${ }^{19}$ However, its deliberate application to induce new, superior functionality in products has only started recently, e.g. in the studies by Ishimoto et al., ${ }^{27}$ Sun et al., ${ }^{31,33}$ etc. Ishimoto et al. clarified the strong texture evolution mechanism in cubic-symmetry materials fabricated by L-PBF, by considering the findings presented in the previous section that "strong texture is developed in the product in which the elongated cells are controlled to be grown along the $z$-direction when observed on the $x$ - $z$ section", ${ }^{2}$ by appropriate selection of L-PBF fabrication process parameters. In addition to the X-scan method presented in the previous section, the XY-scan approach, in which the laser is scanned bidirectionally but with a rotation of $90^{\circ}$ after each layer, is frequently used for product fabrication. The development of completely different textures in some cubic-symmetry materials depending on the scan strategy has been reported in L-PBF products, for example, in Refs. 25,27,31,32. Focusing on the above-mentioned Ti-15Mo-5Zr-3Al alloy, strong $<001>$ and $<110>$ alignment occurs along the scanning $(x)$ and build $(z)$ directions in the sample obtained using the X-scan method, as shown in Figs. 1a and 2e, respectively. By contrast, the XYscan method is known to yield strong $<001>$ alignment along all the $x$-, $y$-, and $z$-directions, ${ }^{27}$ as shown in Fig. $1 b$. 

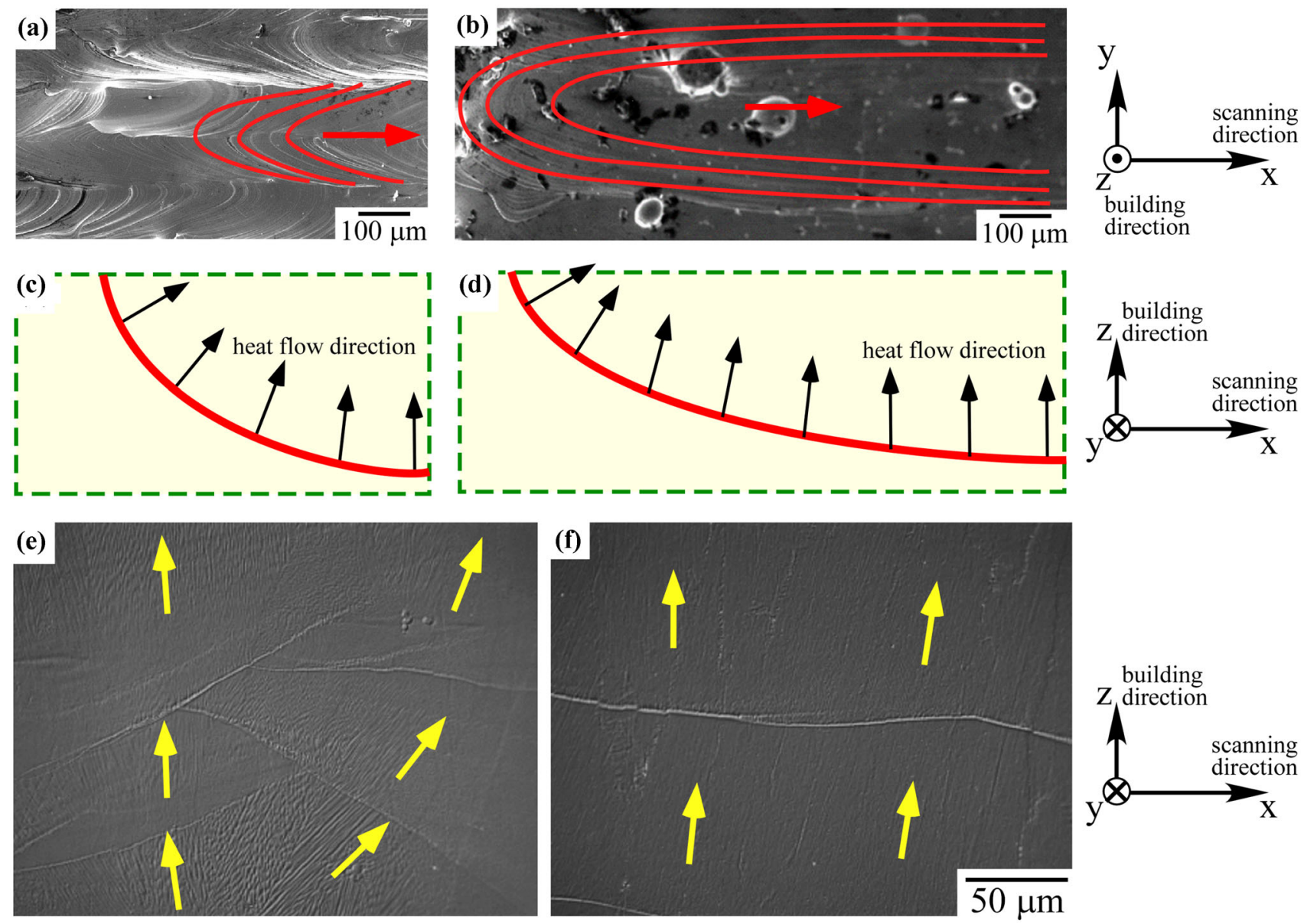

Fig. 3. (a, b) SEM images showing the change in melt-pool shape with scanning speed. (c, d) Schematic indicating the variation in the threedimensional shape of the melt pool. (e, f) Higher-magnification images of microstructure observed on $x-z$ section, showing variation in elongation direction of columnar cells. Samples fabricated under condition $1(a, c, e)$ or $5(b, d, f)$ in Table I. Some figures reprinted from figs. 7 and 8 from Ref. 59 with permission from the Journal of Smart Processing.

The texture formation mechanism depending on the scan strategy as proposed in Ref. 27 is shown schematically in Fig. $1 \mathrm{c}$ and d. For the X-scan sample, observations of the microstructure on the $y-$ $z$ section show boundaries of columnar grains located at the centers of the melt pools. In the left and right half of the melt pool, two directional cell growths elongated along $-45^{\circ}$ and $45^{\circ}$ from the building direction are observed, respectively. SEMEBSD analysis clarified that the crystallographic orientation in the left half of the formerly solidified pool and the right half of the next solidified pool were completely identical. As described previously, the crystallographic direction of the elongated cellular microstructure almost corresponded to $<100>$, which is the preferential growth direction in most cubic-symmetry materials. ${ }^{57}$ It is noteworthy that the cellular microstructure on the $x-z$ section was elongated almost parallel to the build direction when strong texture was developed, as described in the previous section and Fig. 3f. This indicates that the primary and subsequent secondary growths of the cellular microstructure, which were both parallel to $\langle 100\rangle$, occurred predominantly in the plane perpendicular to the scanning direction, under the condition where strong texture evolved. Consequently, the remaining $<001>$ cells were aligned almost parallel to the scanning direction. On the $y-z$ section, the elongated cells at the left and right side of the melt pool meet after migration of the liquid-solid interfaces and form a grain boundary with small angle misorientation at the center of the melt pool. In the equilibrium state of cell growth, they tend to grow along $-45^{\circ}$ and $45^{\circ}$ from the build direction, because the primary and secondary elongation directions of the cell on both sides of the melt pool tend to maintain the $<100>$ direction to facilitate epitaxial growth. As a result of the $\pm 45^{\circ}$ growth in the $<100>$ cells on the $y-z$ section, $<110>$ was preferentially oriented along the build $z$-direction in the X-scan sample.

In contrast, when using the XY-scan approach, observation of the microstructure clarified that the elongated $<100>$ cells generated around the meltpool bottom grew along the build $z$-direction, while the other elongated $<100>$ cells generated around the upper wall of the pool grew vertically with 
respect to the build direction during the $\mathrm{X}$-scan, as indicated in Fig. 1d. In the melt pool generated by the subsequent Y-scan, equivalent cellular growth was observed. This is due to the maintenance of an identical crystal orientation in both scan regions to minimize the interfacial energy derived from epitaxial growth. If the $<100>$-oriented cell growth occurs in $\pm 45^{\circ}$ direction during the XY-scan as observed in the $\mathrm{X}$-scan, $<100>$ cannot grow in a continuous direction in the following Y-scan layer. Thus, such $\pm 45^{\circ}$ growth is not favored in the XYscan. Consequently, $<100>$ was fixed along the two scan $(x$ - and $y$-) and build $z$-directions in the XY-scan sample, as shown in Fig. 1d.

It is noteworthy that, for both the $\mathrm{X}$-and $\mathrm{XY}$-scan methods, the elongated $<100>$ cells grew primarily along two orthogonal directions in the plane perpendicular to the scanning direction (on the $y-z$ section). This fixes another $<001>$ direction along the scanning direction, resulting in the evolution of single-crystal-like, strong crystallographic texture. Hence, the alignment of $<001>$ along the scanning direction because of preferential growth of cells in the $y-z$ section, described in the previous section, becomes the most significant factor governing the texture evolution behavior in cubic-symmetry materials. This finding that the $<100>$ alignment along the scanning direction is the stronger factor differs from conventional thinking, i.e., that the crystal alignment along the build direction is the most important. This conclusion is further validated by a study of L-PBF on single-crystalline starting plates with several different crystal orientations. ${ }^{40}$ Using the abovementioned texture control, Ishimoto et al. successfully reduced the Young's modulus of the implant material along a specific direction. $^{27}$ Following that study, many other papers reporting positive control of the crystal orientation to control product functionality have been published. ${ }^{33,37,38}$

As described above, the melt-pool shape significantly affects the texture development behavior via the change in the growth direction of the elongated cells. Because the melt-pool shape varies with the energy density during L-PBF, as shown in the previous section, texture variations depending on the laser power are expected under specific circumstances. Sun et al. reported the variation in the texture of stainless steel $316 \mathrm{~L}$, where the preferential alignment along the build direction could be changed from $<001>$ to $<011>$ by increasing the laser power combined with a change in scan strategy between a single scan and bidirectionally scan perpendicular to the melt-pool elongation direction. ${ }^{30}$ They suggested a relationship between the melt-pool geometry and crystallographic texture formation based on kinetic Monte Carlo simulations. ${ }^{30}$ The formation of a shallower (flattened) melt pool induced growth of elongated cells along the vertical growth, resulting in the formation of $<001>$ texture.
Furthermore, Sun et al. recently reported the evolution of "hybrid" $<001>$ and $<011>$ textures in an X-scan product, as shown in Fig. 4, afforded by appropriate process parameter control. ${ }^{33}$ This unique texture is known as the "crystallographic lamellar microstructure" (CLM). The crystallographic orientation relationship between the major and minor regions, shown by green and red in Fig. 4c, respectively, are as follows:

In x-axis: major $<100>/ /$ minor $<1 \overline{1} 0>$
In y-axis: major $<01 \overline{1}>/ /$ minor $<110>$
In z-axis: major $<011>/ /$ minor $<001>$

That is, the texture in the major region is the same as that observed in the single-crystalline specimens shown in Figs. 1a and $4 \mathrm{~b}$, but the texture in the minor region is rotated by $90^{\circ}$ around the $y$ axis with respect to the major region. This indicates that the basic texture formation mechanism of the CLM is similar to that of the $<011>$ texture shown in Fig. 1c; however, the $<001>$-textured cells were elongated along the vertical direction only at the center of the melt pool, where the curvature of the melt-pool boundary was smallest, as shown in Fig. 4c. Note that the texture at the central minor region is similar to that developed in the XY-scan product shown in Fig. 1b, but rotated by $45^{\circ}$ around the $z$-axis. This might be owing to the epitaxial growth of cells in the minor region with respect to the major region, while maintaining the vertical growth of the cells along the build $z$-direction. It was found that the development of CLM primarily improved the material properties of stainless steel $316 \mathrm{~L}$ via strengthening of the product, simultaneously showing corrosion resistance superior to commercially obtained specimens. ${ }^{33}$ The development of CLM was also recently reported in an Inconel 718 Ni-based superalloy. ${ }^{41}$

Note that the validity of this idea to understand the texture formation mechanism by focusing on the melt-pool shape has recently been reported for not only L-PBF but also EB-PBF products ${ }^{62}$ (Fig. 5). EB-PBF with higher heat-source energy induces the formation of a melt pool with flattened shape. This induces vertical growth of columnar cells along the $z$-direction even in the $\mathrm{X}$-scan mode, as shown in Fig. 5c. As a result, the same texture as observed in the XY-scan product in Fig. 5d is developed, in contrast to the L-PBF case. This is the reason described in the "Introduction" for why the texture control is limited in EB-PBF compared with L-PBF products.

\section{LOCAL CONTROL OF TEXTURE BY CHANGING SCANNING STRATEGY AT EACH POSITION}

The advantage of AM is that the scan strategy can be changed depending on the position in the product. As described in the previous section, changing 

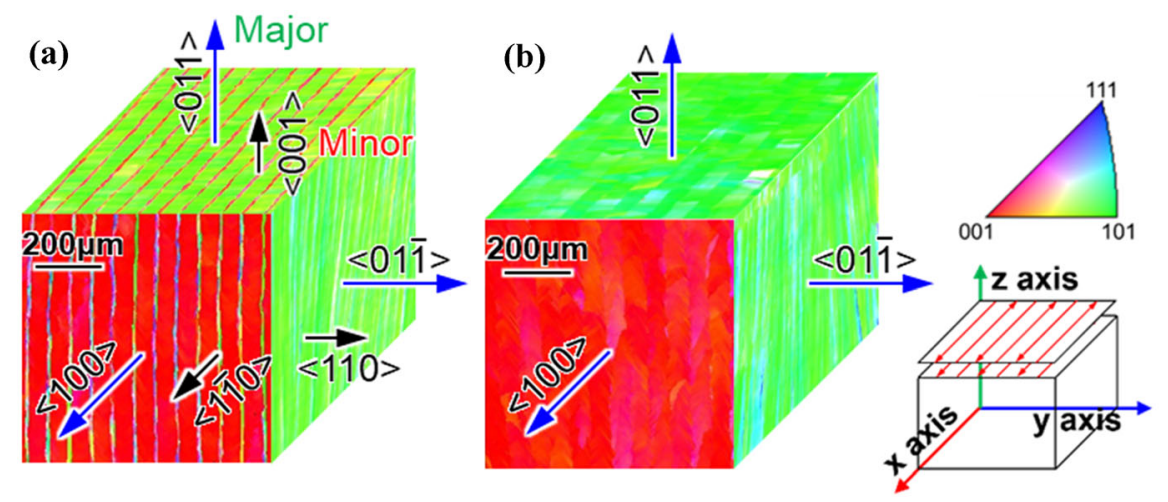

IPF map along z-direction
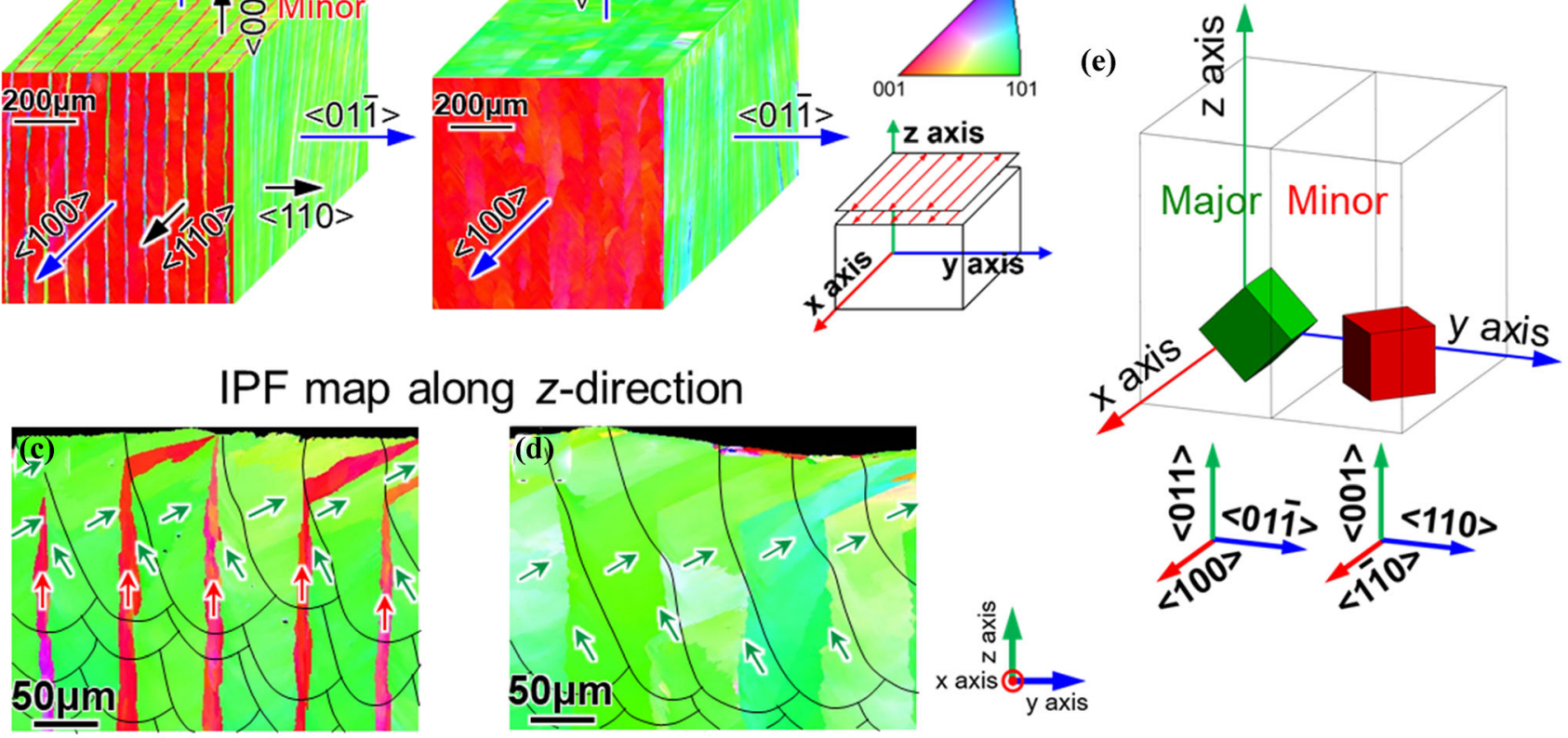

Fig. 4. (a-d) Crystal orientation maps in stainless steel 316 specimens fabricated using the X-scan strategy with (a) crystallographic lamellar microstructure (CLM) and (b) single-crystalline texture, observed along $x-, y$-, and $z$-direction, respectively, by SEM-EBSD. (c, d) Corresponding higher-magnification crystal orientation maps along $z$-axis, observed at top surface of samples on $y-z$ section. Arrows indicate direction of cell elongation as $\pm 45^{\circ}$ (green) or vertically oriented (red). (e) Schematic illustration showing crystallographic orientation relationship between major and minor regions in CLM. Figures reprinted from figs. 1 and 2 from Ref. 33 with minor modification under the terms of the Creative Commons CC-BY license (Color figure online).

the scan strategy during L-PBF can change the evolution of the texture in the product, i.e., the evolution of the $\langle 110\rangle$ texture in the X-scan and $<100>$ texture in the XY-scan, along the build $z$ direction. Hence, a method enabling precise localized texture control (resulting in mosaic-like texture) is required to achieve products with enhanced functionality; For example, the strength and Young's modulus of Ti-15Mo-5Zr-3Al alloy for use in biomedical implants must be adjusted appropriately to adapt to the stress field in the actual application in vivo to reduce stress shielding of bone, ${ }^{63}$ as shown conceptually in Fig. 6a. In conventional processes such as casting and forging, such localized control of texture is impossible; however, it is possible when using AM by changing the scan strategy accordingly, as shown in Fig. 6b.

One of the first studies targeting localized texture control in L-PBF was conducted by Geiger et al. ${ }^{25}$ They focused on L-PBF of Inconel 738LC using three different scan strategies, i.e., XY-scan, $+45 \%$ - $45^{\circ}$ scan, and $67^{\circ}$-rotation scan, in each layer. By changing the scan strategy in a specimen, they demonstrated that texture and elastic anisotropy could be customized along the build-up direction by stacking different scanning regimes during the sequential build-up process at each position. Some related studies pertaining to not only L-PBF ${ }^{39,64,65}$ but also $\mathrm{EB}^{-\mathrm{PBF}^{15,66}}$ have also been reported. In case of EB-PBF, the focus is mainly of the mixture of $<001>$ growth and random-oriented growth. Sofinowski et al. reported locally customized L-PBF manufacturing for stainless steel $316 \mathrm{~L}{ }^{39}$ They successfully embedded cylinder-like controlled texture and changed the local texture pointwise with high spatial resolution. In addition, they reported a unique variation in texture by changing the scan direction by $1^{\circ}$ in each layer.

It is noteworthy that, in the study by Sofinowski et al., at every $1^{\circ}$ rotation of the scan direction, it seems that the texture did not show a continuous change but a discrete variation. ${ }^{39}$ This implies the appearance of a transient region in the texture when the scan strategy is changed during L-PBF. This was clearly elucidated in a recent study. ${ }^{40}$ Figure $7 \mathrm{a}, \mathrm{b}, \mathrm{c}, \mathrm{d}$, e and $\mathrm{f}$ shows crystal orientation maps measured in a Ti-15Mo-5Zr-3Al sample where the scan strategy was changed periodically during the L-PBF fabrication process. In that study, two different scan variation schemes were applied, alternating between $\mathrm{X}$-scan and $\mathrm{XY}$-scan as shown in Fig. $7 \mathrm{a}, \mathrm{b}$ and $\mathrm{c}$ or between $\mathrm{X}$-scan and Y-scan as shown in Fig. $7 d$, e and f. The scan strategy was changed every 30 layers. Figures $7(\mathrm{a}, \mathrm{d}),(\mathrm{b}, \mathrm{e})$, and $(c, f)$ indicate the crystal orientation colors when analyzed along the $x$-, $y$-, and $z$-direction, respectively, on $y-z$ cross-section. In Fig. 7, the positions at which the scan strategy was changed are indicated 


\section{X-Scan}
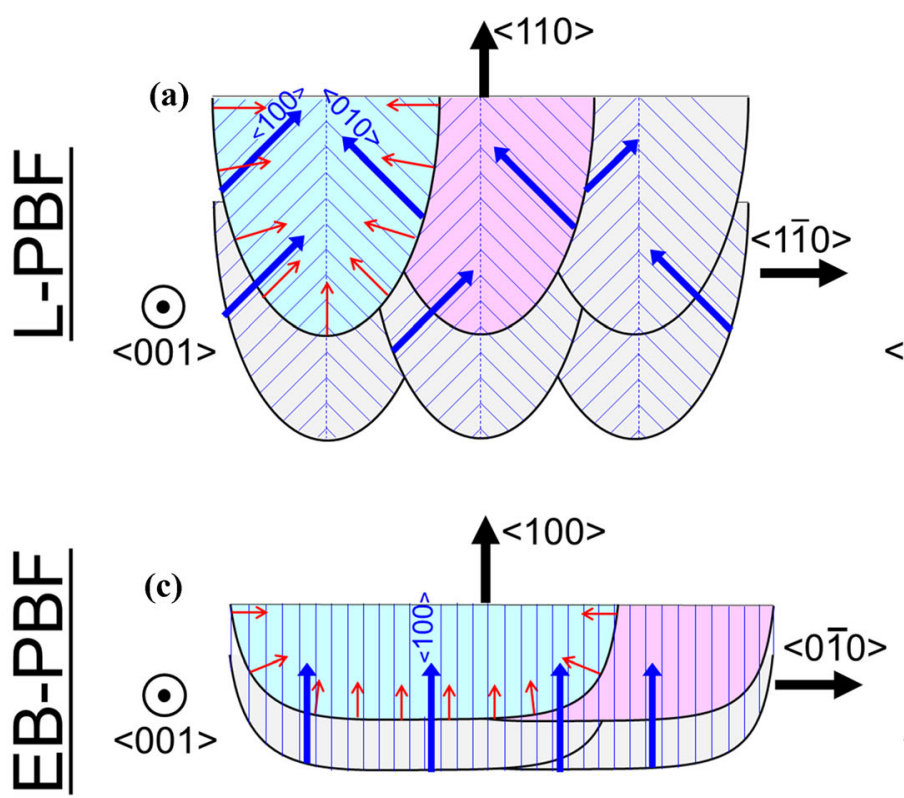

(b)

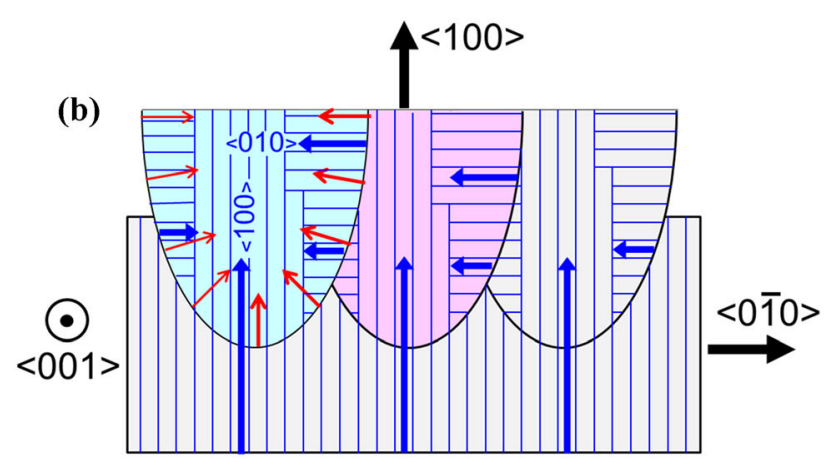

(d)

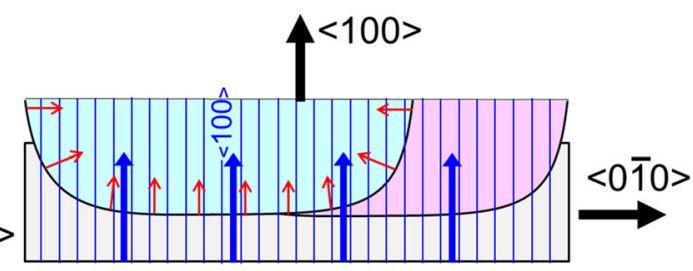

$$
\uparrow \underset{\text { gradient direction }}{\text { Maximum thermal }} \uparrow \begin{gathered}
\text { Growth direction of } \\
\text { the elongated cell }
\end{gathered}
$$

Fig. 5. Schematics showing the differences in evolution behavior of crystallographic texture between L-PBF and EB-PBF products: (a) X-scan in L-PBF, (b) XY-scan in L-PBF, (c) X-scan in EB-PBF, and (d) XY-scan in EB-PBF. Figures reprinted from fig. 15 in Ref. 62 under the terms of the Creative Commons CC-BY license.

by horizontal gray lines. The evolution of the mosaic-like texture was confirmed for both changing schemes, demonstrating the effectiveness of scan strategy control in L-PBF, as described above. It is noteworthy that the transient behavior of the texture differed depending on the scan strategy. When alternating between $\mathrm{X}$-scan and XY-scan, the area fractions where $\langle 110\rangle$ and $<100>$ textures evolved differed significantly. Nevertheless, the scan strategy was changed alternatively with the same period of 30 layers. As shown in Fig. $7 \mathrm{~b}$ and c, which show the crystal orientations along the $y$ - and $z$-direction, respectively, the area fraction exhibiting $<100>$ texture indicated by red was much wider than that exhibiting $<110>$ texture indicated by green.

Furthermore, when alternating between X-scan and Y-scan as shown in Fig. 7d, e and f, the nature of the evolved texture itself was changed by the alternation of the scan strategy. In the ideal X-scan, crystal orientation alignments of $\langle 100\rangle,\langle 011\rangle$, and $\langle 01 \overline{1}\rangle$ are expected along the $x-, y$-, and $z$ direction, respectively, as shown in Fig. 1c. Similarly, in the ideal Y-scan, the evolution of $<011>$, $<100>$, and $<01 \overline{1}>$ crystal orientation alignment is expected along the $x$-, $y$-, and $z$-direction, respectively. Hence, when focusing on the crystal orientation along the $z$-direction, only alignment along $<01 \overline{1}>$ (shown in green) is expected, since $<01 \overline{1}>$ is the typical direction in the texture evolved in the $\mathrm{X}$-scan and Y-scan samples. However, the observations in Fig. $7 \mathrm{f}$ demonstrate that an unexpected $<100>$ texture (shown in red), with $<100>$ aligned along the $z$-direction, evolved in the transient zone between the X-scan and Y-scan, with a relatively large area fraction.

These results demonstrate that the texture formation mechanism is not governed only by the scan strategy, but also the "texture stability," associated with the ease of epitaxial growth of columnar cells with respect to the preexisting base (matrix), plays an important role. The "texture stability" was further quantitatively discussed in the study using single-crystalline starting plates. ${ }^{40}$

\section{TEXTURE EVOLUTION IN NONCUBIC MATERIALS; CRYSTAL SYMMETRY AS CONTROLLING FACTOR}

One of the well-known merits of AM is that it can be used to fabricate products with complex geometries that cannot be fabricated using standard manufacturing techniques; this includes high-temperature structural materials, which often exhibit brittleness at room temperature. ${ }^{67-76}$ Fabrication of ceramic materials such as alumina, silicon carbide, calcium phosphate, and zirconia via selective laser processing including SLM (L-PBF) and selective 
(a)

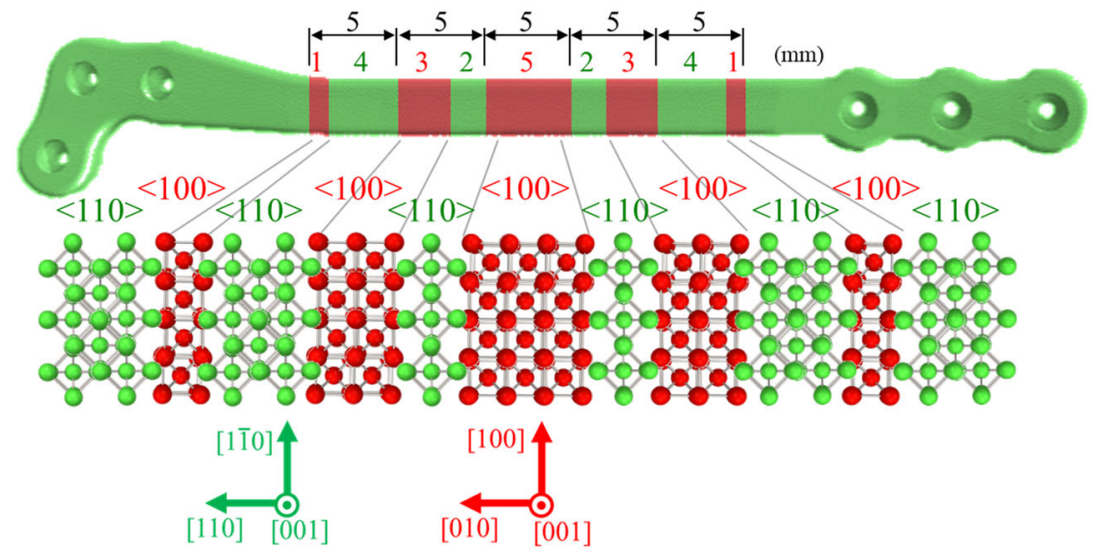

(b)

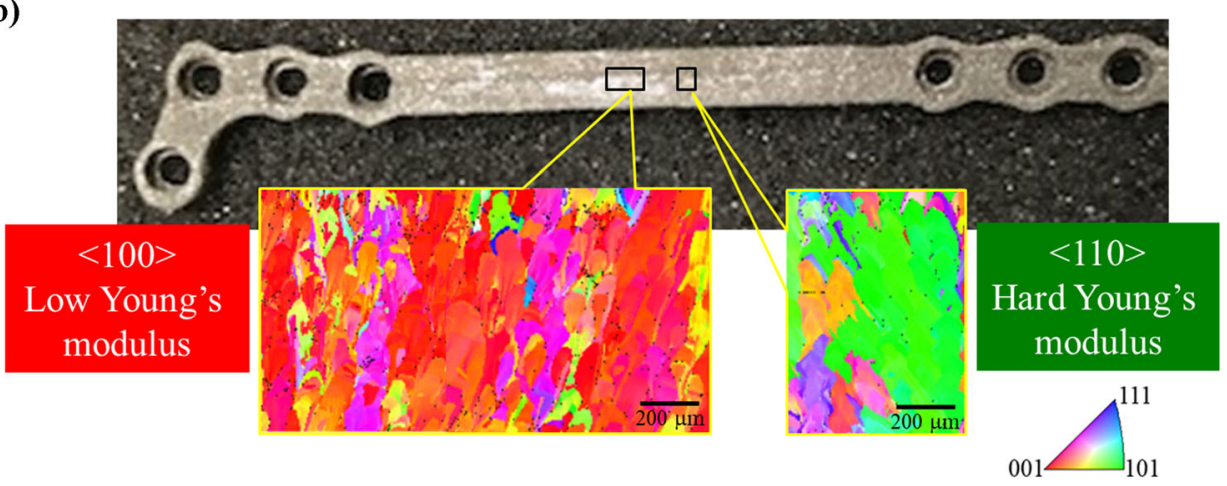

Fig. 6. (a) Conceptual illustration showing localized control of texture (mosaic-like texture) in bone plate implant used for fixating fractures. (b) The real product in which mosaic-like texture was developed, fabricated by L-PBF in our group.

X-scan / XY-scan

$x$-direction $y$-direction $z$-direction $\begin{gathered}\text { Scanning } \\ \text { strategy }\end{gathered}$ (b) $f$ III (c)

(a) 1.7. (b)

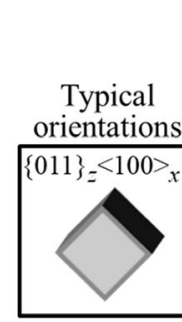

$\{001\}<<100>x$ (c):
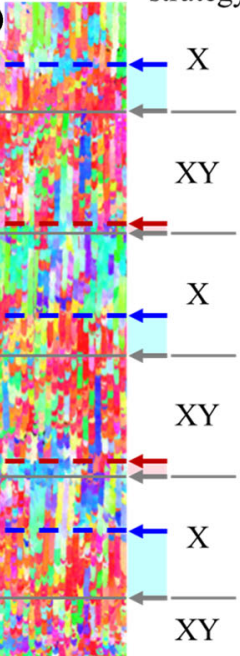

\section{X-scan / Y-scan}

Typical
orientations $\quad x$-direction $y$-direction $z$-direction $\begin{gathered}\text { Scanning } \\ \text { strategy }\end{gathered}$

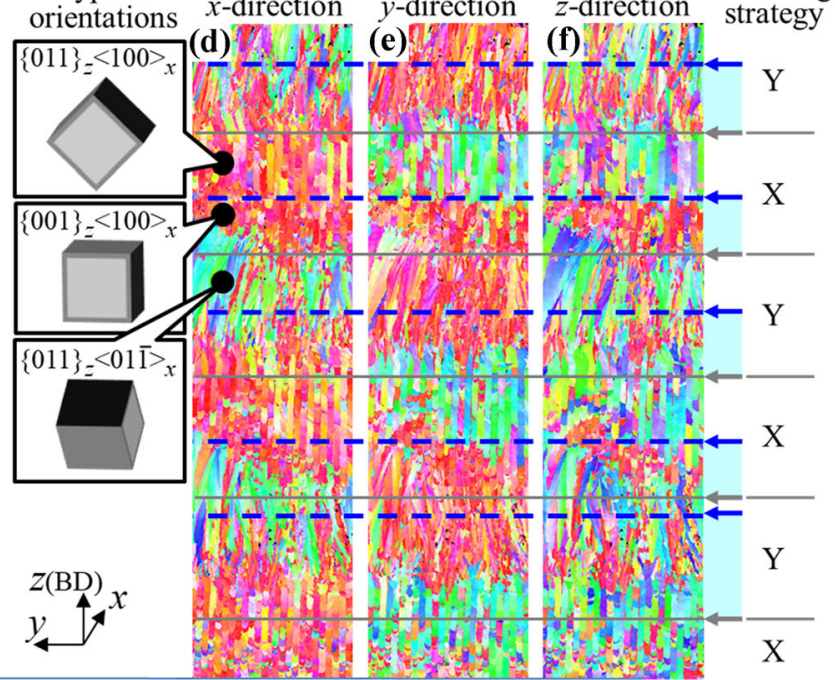

$$
\begin{aligned}
\hline \text { Transient zone } & \leftarrow \text { End point of transition zone } \\
& \leftarrow \text { Point of scanning strategy change }
\end{aligned}
$$

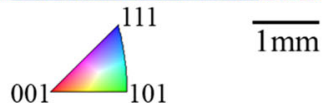

Fig. 7. Crystal orientation maps showing variation in texture by changing scanning strategy during fabrication of bcc-Ti-15Mo-5Zr-3Al samples by alternating changes between $(\mathrm{a}-\mathrm{c}) \mathrm{X}$-scan and $\mathrm{XY}$-scan, and $(\mathrm{d}-\mathrm{f}) \mathrm{X}$-scan and $\mathrm{Y}$-scan. Observations on $y-z$ section; colors indicate crystal orientation along $(\mathrm{a}, \mathrm{d}) x^{-},(\mathrm{b}, \mathrm{e}) y^{-}$, and $(\mathrm{c}, \mathrm{f}) z$-direction. Positions where the scanning strategy changed are indicated by horizontal gray lines, and positions where the resultant change in texture occurred are indicated by dashed blue and red lines. Figures reprinted from fig. 2 in Ref. 40 under the terms of the Creative Commons CC-BY license. 
laser sintering (SLS) has been conducted. ${ }^{77-81}$ However, texture control of such ceramic materials has been little reported. ${ }^{82}$

We recently reported L-PBF fabrication of transition-metal disilicide products $\mathrm{C} 11_{\mathrm{b}}-\mathrm{MoSi}_{2}{ }^{55}$ and C40-NbSi $2,{ }^{56}$ which are expected to be used at temperatures exceeding $1200{ }^{\circ} \mathrm{C}$. If texture development can be controlled in these products, their high-temperature strength and creep resistance could be improved. ${ }^{83-86}$ The cited study revealed that the texture formation behaviors in these silicides differed significantly from those observed in cubic-structured (fcc, bcc) materials described in the previous section.

Figure 8 shows representative pole figures of LPBF-fabricated samples of (a) cubic (bcc) Ti-15Mo$5 \mathrm{Zr}-3 \mathrm{Al}^{27}$ (b) tetragonal $\mathrm{MoSi}_{2},{ }^{55}$ and (c) hexagonal $\mathrm{NbSi}_{2} \cdot{ }^{56}$ In bcc-Ti, different single-crystalline textures with $<011>$ and $<100>$ aligned along the build direction were developed using the X-scan and XY-scan strategies (Fig. 1). However, the features of the texture for tetragonal $\mathrm{MoSi}_{2}$ and hexagonal $\mathrm{NbSi}_{2}$ were different. In tetragonal $\mathrm{MoSi}_{2}$, a singlecrystalline texture was developed in the X-scan sample, with the build $z$ - and scanning $x$-directions parallel to $<100$ ] and [001], respectively. However, only a fiber-like texture with the build $z$-direction parallel to $<100$ ] was developed without a singlecrystalline texture in the XY-scan sample. Here, the mixed notation of $\{h k l)$ and $<u v w]$, which differentiates the first two indices from the third that does not play the same role as the first two, is used for $\mathrm{MoSi}_{2}$ because of the tetragonality of the $\mathrm{C} 11_{\mathrm{b}}$ crystal structure. By contrast, only a fiber-like texture with [0001] parallel to the build $z$-direction was developed in both the X-and XY-scan samples in hexagonal $\mathrm{NbSi}_{2}$. These different texture evolution features derive from the difference in crystal symmetry, which affects the "multiplicity" of the preferential growth direction in them, as summarized in Fig. 9.

The $\mathrm{C}_{11} 1_{\mathrm{b}}$ structure in $\mathrm{MoSi}_{2}$ contains a tetragonal unit cell, wherein three bcc lattices are stacked along the $c$-axis as shown in Fig. 9a. The preferential growth direction of the elongated cells in $\mathrm{MoSi}_{2}$ was parallel to $<100] .{ }^{55}$ In L-PBF of $\mathrm{MoSi}_{2}$, growth of the columnar cells occurred primarily in the plane perpendicular to the scanning $x$-direction in samples with strong texture, similar to that explained for Fig. 3f. Hence, in the X-scan sample, preferential growth of the cells parallel to $<100$ ] and subsequent lateral growth parallel to $<010]$ occurred on the $y-z$ section because the [100] and [010] directions are crystallographically equivalent in the tetragonal crystal. Consequently, [001], which is perpendicular to both [100] and [010], aligned along the scanning $x$-direction. Hence, a single-crystalline texture developed, similar to the fcc and bcc materials.

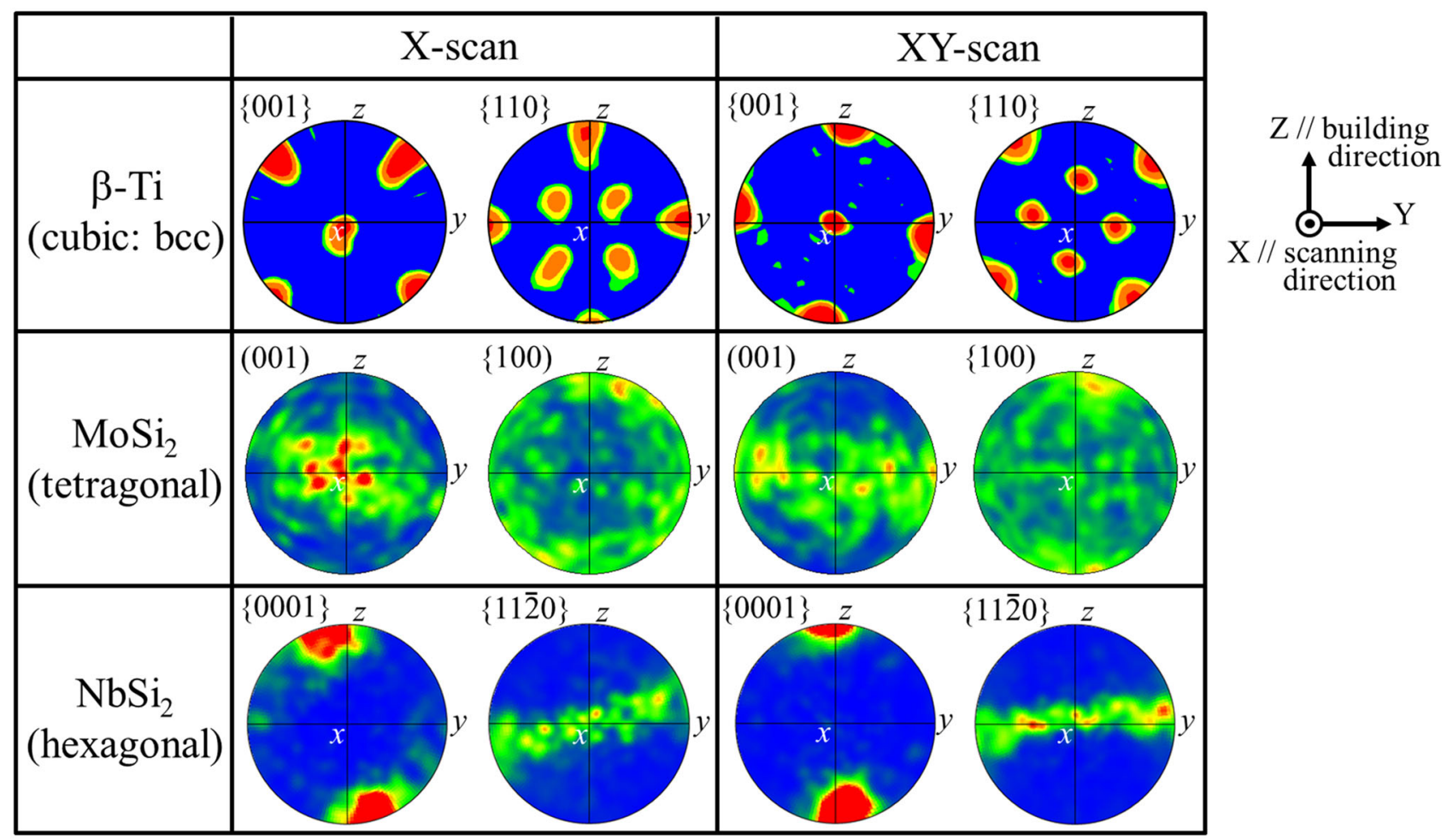

Fig. 8. Comparison of variations in pole figures with scan strategy in cubic (bcc) Ti-15Mo-5Zr-3Al, tetragonal $\mathrm{MoSi}_{2}$, and hexagonal $\mathrm{NbSi}_{2}$. Figures reprinted under the terms of the Creative Commons CC-BY license from fig. 1 in Ref. 27, fig. 2 in Ref. 55, and fig. 3 in Ref. 56, hence the intensity level for pole figure is not normalized in each material. Details regarding L-PBF fabrication conditions for each sample are available in Refs. 27,55,56. 


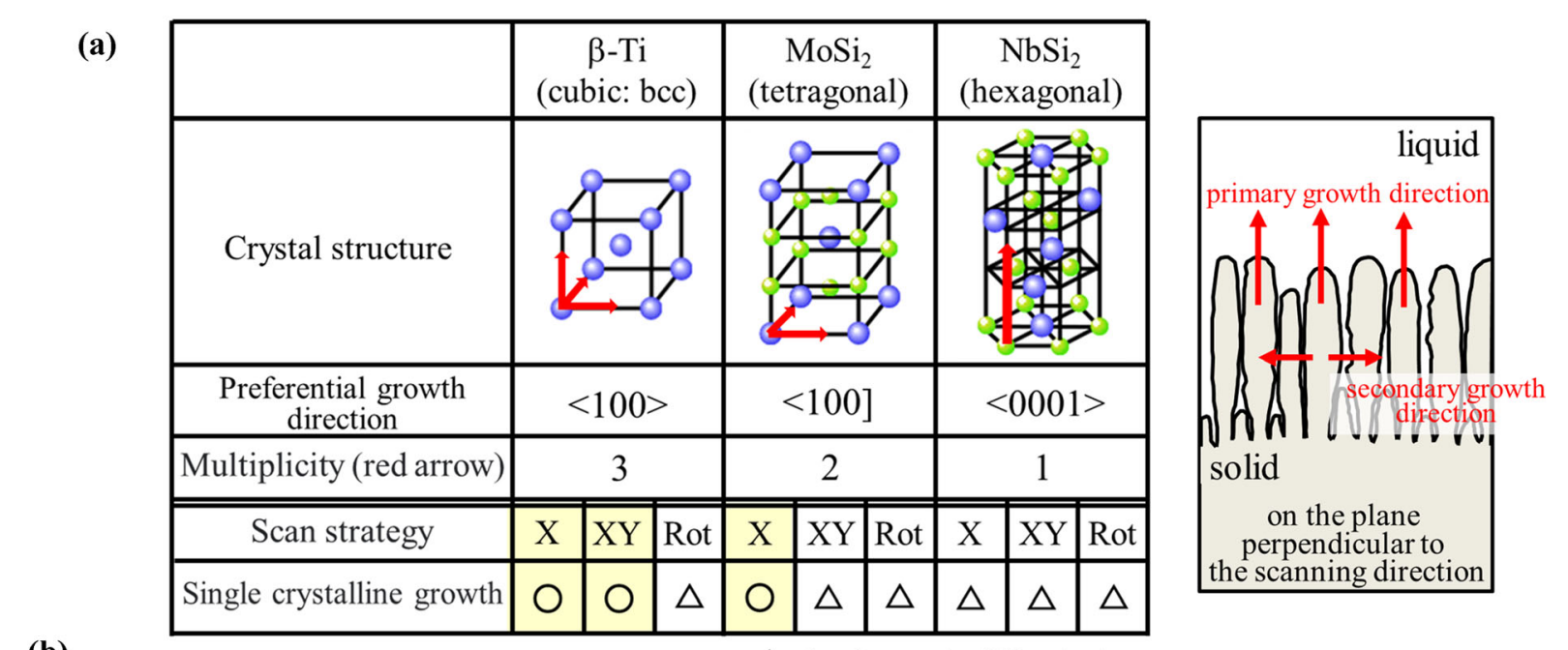

(b)
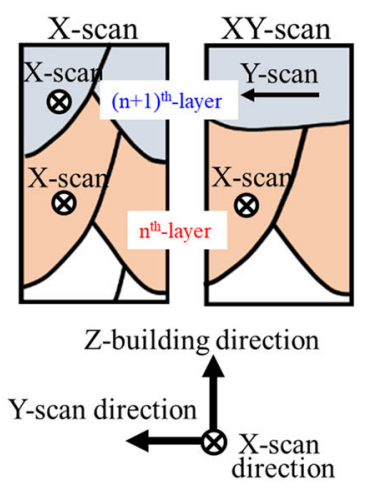

$\triangle$ : development of fiber-texture
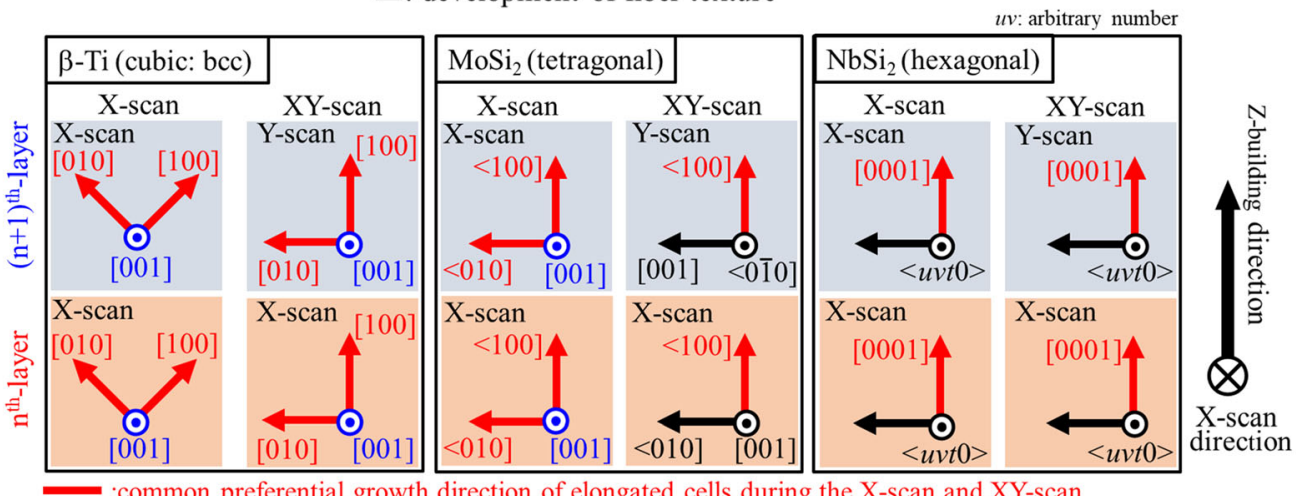

- :common direction during the X-scan and XY-scan, "as a result" of preferential growth (red arrow)

Fig. 9. (a) Relationship among crystal structure, preferential growth direction of elongated cell, and texture developed in L-PBF. (b) Schematic illustration of variations in developing features of texture with crystal structures during X-scan and XY-scan processes in cubic (bcc) Ti-15Mo-5Zr$3 \mathrm{Al}$, tetragonal $\mathrm{MoSi}_{2}$, and hexagonal $\mathrm{NbSi}_{2}$. Figures reprinted from fig. 5 in Ref. 56 under the terms of the Creative Commons CC-BY license (Color figure online).

In the case of the XY-scan in $\mathrm{MoSi}_{2}$, however, the crystal orientations in the first $\mathrm{X}$-scan and the following Y-scan regions could not be matched, unlike the cases of fcc and bcc materials. This is because the $a$-axis and $c$-axis are not crystallographically equivalent in tetragonal $\mathrm{C} 11_{\mathrm{b}}-\mathrm{MoSi}_{2}$ as shown in Fig. 9a. Hence, a single-crystalline texture could not be developed for $\mathrm{C}_{1} 1_{b}-\mathrm{MoSi}_{2}$ in the XYscan, and only a weak fiber texture, with the $<100$ ] cell growth direction parallel to the building $z$ direction, developed in the XY-scan sample as shown in Fig. $8 b$.

In L-PBF of hexagonal $\mathrm{NbSi}_{2}$, the preferred cell growth direction was $<0001>{ }^{56}$ It is noteworthy that $<0001>$ is only one direction in the unit cell of the hexagonal crystal. This differs from $<100>$ in cubic materials, wherein the three directions are parallel to $<100>$. Moreover, this differs from $<100]$ in tetragonal $\mathrm{C}_{1} 1_{\mathrm{b}}-\mathrm{MoSi}_{2}$, wherein the two directions are parallel to $<100$ ] in the unit cell, as denoted by the crystallographic multiplicity in Fig. 9a with red arrows. Hence, during the growth process of the elongated cells in $\mathrm{NbSi}_{2}$, the primary elongation direction was parallel to $<0001>$, but the subsequent lateral growth (secondary growth) direction on the $y-z$ section was arbitrary because only one $<0001>$ axis exists in the hexagonal crystal. Therefore, a single-crystalline texture was absent, and a fiber-like texture developed, with only $<0001>$ parallel to the build direction, in hexagonal $\mathrm{NbSi}_{2}$. This occurred similarly in the XY-scan. Hence, no significant changes were observed in the texture of the samples. It is noteworthy that similar texture formation was reported in a hexagonal close-packed $\mathrm{Mg}$ alloy. ${ }^{87}$ To develop such fiber-like texture in cubic materials, a $67^{\circ}$ rotation scan should be performed after each layer (Rot-scan). ${ }^{31}$

\section{FUTURE PERSPECTIVES REGARDING TEXTURE CONTROL IN AM}

As explained above, future technologies for AM of metals and ceramics will evolve not only as traditional recognition-based shape control tools, but also as innovative tools that allow free control of crystal orientation and microstructure. The combination of 


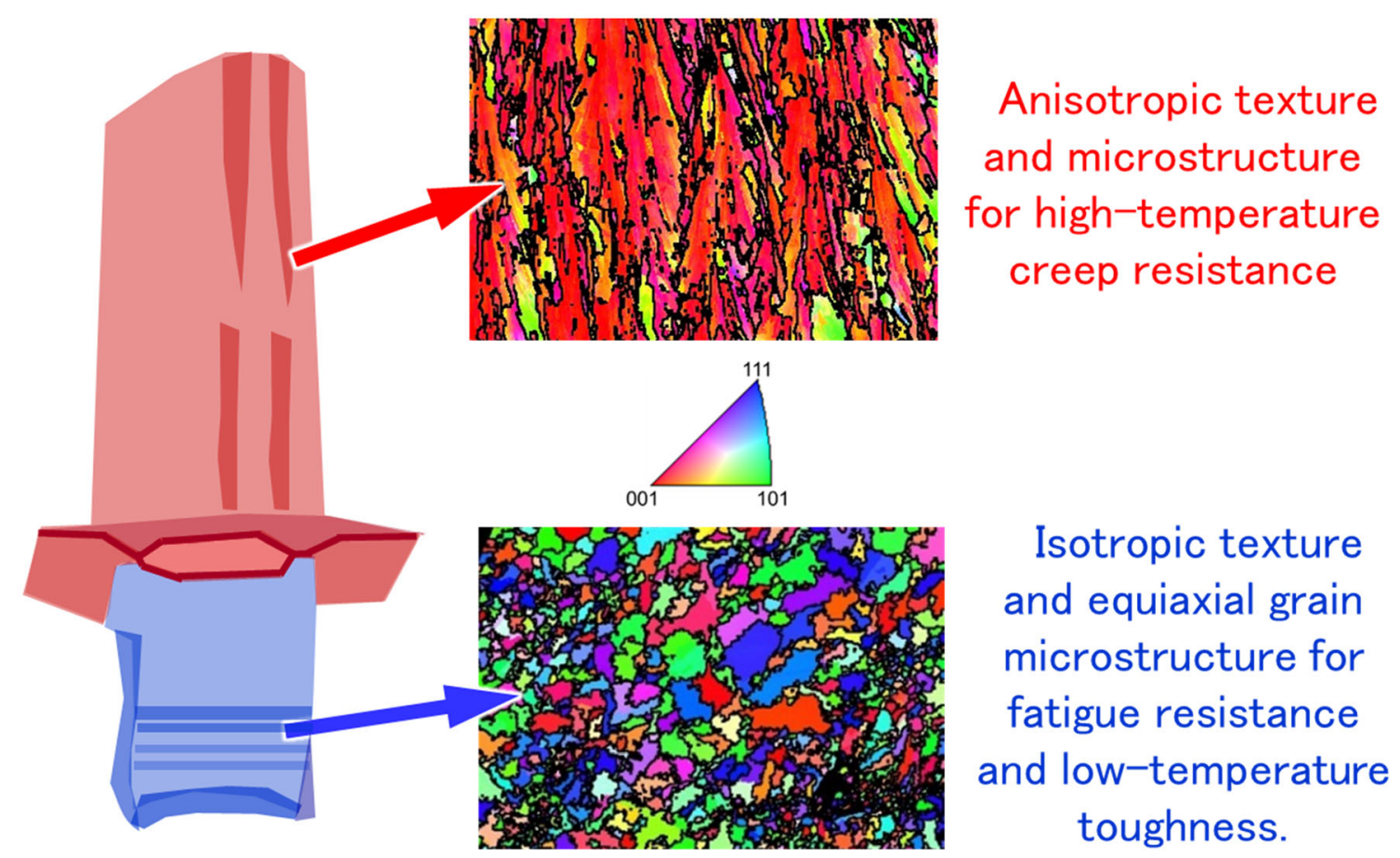

Fig. 10. Conceptual diagram of high-performance turbine blades that can be manufactured only by using the AM process. (The EBSD map is just an image that conceptually shows columnar grains and equiaxed grains, not taken from an actual Ni-based superalloy).

arbitrary shape control with control of material properties via texture control will enable the development of high-performance products not realizable to date. One example is the development of the highfunctionality implant material shown in Fig. 6 . Another example that focuses on aerospace components is high-performance turbine blades. As shown in Fig. 10, the portion of the blade that receives centrifugal force due to rotation is composed of columnar grains or single crystal whose crystallographic orientation is controlled, while the lower, fixed portion is composed of random polycrystalline equiaxial grains to ensure fatigue resistance and low-temperature toughness. In these ways, multifunctional products that cannot be manufactured by conventional casting technology will be developed in the near future by focusing on simultaneous control of shape and texture in AM products for application in various fields.

To expand such applications, it is desired to increase the number of materials whose texture can be controlled during the AM process. As described herein, the potential for texture control has been found for many metals and some ceramics, regardless of their crystal structure. However, texture control by AM has not yet been fully achieved in Ti-6Al-4V, ${ }^{19,88-92}$ which is important as a biomaterial, or TiAl alloys, ${ }^{93-98}$ which are important as a high-temperature heat-resistant materials. The reason is that both of these alloys exhibit solid-state phase transformation at high temperatures. Since texture control by AM is based on control over the solidification process, it is difficult to suppress the destruction of the texture by solid-state phase transformation during the cooling process. Texture control in such materials might be achieved by achieving variant control during the phase transformation via cooling under stress loading or a magnetic field, ${ }^{99}$ although this requires further investigation.

\section{CONCLUSION}

Although precise shape control during fabrication has been prioritized in AM, texture control is also important because it is a unique feature of metal AM. The recent developments described herein enable intentional control of the texture in a product. The combination of precise texture control with complicated, near-net-shape control enables a hierarchical structure to be created, in which the properties are isotropically or anisotropically controlled in different scales from atomistic to millimeter scale, hence enabling unprecedented superior properties.

To control the texture in L-PBF samples, the following must be considered:

1. The L-PBF process parameters must be controlled to achieve two-dimensional growth of columnar cells, restricted to the $y-z$ section perpendicular to the scanning $x$-direction, such that the evolution to strong texture can be realized. 
2. The alignment of $<001>$ along the scanning direction, as a result of the preferential growth of cells on the $y-z$ section, is the most significant factor governing the texture evolution behavior in cubic (fcc, bcc) materials.

3. The texture formation mechanism is governed not only by the scan strategy but also by the texture stability, which is associated with the ease of epitaxial growth of columnar cells with respect to the preexisting base (matrix).

4. In materials with noncubic crystal symmetry, different textures develop as compared with those observed in cubic materials. The crystallographic multiplicity of the preferential crystal growth direction is one of the primary factors governing the features of their textures.

\section{CONFLICT OF INTEREST}

The authors declare that they have no conflicts of interest.

\section{ACKNOWLEDGEMENTS}

This study was supported by Grants-in-Aid for Scientific Research (JP18H05254) from the Japan Society for the Promotion of Science (JSPS). This study was also partly supported by the Cross-Ministerial Strategic Innovation Promotion Program (SIP) and Materials Integration for Revolutionary Design System of Structural Materials, Domain C1 "Development of Additive Manufacturing Process for Ni-based Alloy" from the Japan Science and Technology Agency (JST).

\section{OPEN ACCESS}

This article is licensed under a Creative Commons Attribution 4.0 International License, which permits use, sharing, adaptation, distribution and reproduction in any medium or format, as long as you give appropriate credit to the original author(s) and the source, provide a link to the Creative Commons licence, and indicate if changes were made. The images or other third party material in this article are included in the article's Creative Commons licence, unless indicated otherwise in a credit line to the material. If material is not included in the article's Creative Commons licence and your intended use is not permitted by statutory regulation or exceeds the permitted use, you will need to obtain permission directly from the copyright holder. To view a copy of this licence, visit http://creativecommons.org/licenses/by/4.0/.

\section{REFERENCES}

1. N. Guo and M.C. Liu, Front. Mech. Eng. 8, 215. (2013).

2. D. Herzog, V. Seyda, E. Wycisk, and C. Emmelmann, Acta Mater. 117, 371. (2016).

3. C. Köroner, Int. Mater. Rev. 61, 361. (2016).

4. A. Townsend, N. Senin, L. Blunt, R.K. Leach, and J.S. Taylor, Precis. Eng. 46, 34. (2016).
5. V. Bhavar, P. Kattire, V. Patil, S. Khot, K. Gujar, and R. Singh, Additive Manufacturing Handbook (CRC Press, Boca Raton, 2017), pp 251-253.

6. T. DebRoy, H.L. Wei, J.S. Zuback, T. Mukherjee, J.W. Elmer, J.O. Milewski, A.M. Beese, A. Wilson-Heid, A. De, and W. Zhang, Prog. Mater. Sci. 92, 112. (2018).

7. S.F. Shirazi, S. Gharehkhani, M. Mehrali, H. Yarmand, H.S. Metselaar, N. Adib Kadri, and T.A. Osman, Sci. Technol. Adv. Mater. 16, 033502. (2019).

8. J. Plocher and A. Panesar, Mater. Des. 183, 108164. (2019).

9. L. Bai, C. Gong, X. Chen, Y. Sun, J. Zhang, L. Cai, S. Zhu, and S.Q. Xie, Metals 9, 1004. (2019).

10. P. Wang, X. Li, Y. Jiang, M.L.S. Nai, J. Ding, and J. Wei, Addit. Manuf. 36, 101556. (2020).

11. M. Orme, I. Madera, M. Gschweitl, and M. Ferrari, Designs 2, 51. (2018).

12. P. Wang, J. Song, M.L.S. Nai, and J. Wei, Addit. Manuf. 33, 101088. (2020).

13. G.P. Dinda, A.K. Dasgupta, and J. Mazumder, Scr. Mater. 67, 503. (2012).

14. A.A. Antonysamy, J. Meyer, and P.B. Prangnell, Mater. Charact. 84, 153. (2013).

15. H. Helmer, A. Bauereiß, R.F. Singer, and C. Körner, Mater. Sci. Eng. A 668, 180. (2016).

16. M. Ramsperger, R.F. Singer, and C. Körner, Metall. Mater. Trans. A 47A, 1469. (2016).

17. P. Wang, P. Huang, F.L. Ng, W.J. Sin, S. Lu, M.L.S. Nai, Z. Dong, and J. Wei, Mater. Des. 168, 107576. (2019).

18. L. Thijs, F. Verhaeghe, T. Craeghs, J. Van Humbeeck, and J.P. Kruth, Acta Mater. 58, 3303. (2010).

19. S.S. Al-bermani, M.L. Blackmore, W. Zhang, and I. Todd, Metall. Mater. Trans. A 41A, 3422. (2010).

20. L. Thijs, K. Kempen, J.P. Kruth, and J.V. Humbeeck, Acta Mater. 61, 1809. (2013).

21. B. Vrancken, L. Thijs, J.P. Kruth, and J. Van Humbeeck, Acta Mater. 68, 150. (2014).

22. X. Zhou, K. Li, D. Zhang, X. Liu, J. Ma, W. Liu, and Z. Shen, J. Alloys Compd. 631, 153. (2015).

23. K. Kunze, T. Etter, J. Grässlin, and V. Shklover, Mater. Sci. Eng. A 620, 213. (2015).

24. H.L. Wei, J. Mazumder, and T. DebRoy, Sci. Rep. 5, 16446. (2015).

25. F. Geiger, K. Kunze, and T. Etter, Mater. Sci. Eng. A 661, 240. (2016).

26. M. Fischer, D. Joguet, G. Robin, L. Peltier, and P. Laheurte, Mater. Sci. Eng. C 62, 852-859. (2016).

27. T. Ishimoto, K. Hagihara, K. Hisamoto, S.H. Sun, and T. Nakano, Scr. Mater. 132, 34. (2017).

28. N. Nadammal, S. Cabeza, T. Mishurova, T. Thiede, A. Kromm, C. Seyfert, L. Farahbod, C. Haberland, J.A. Schneider, P.D. Portella, and G. Bruno, Mater. Des. 134, 139. (2017).

29. B. AlMangour, D. Grzesiak, and J.-M. Yang, J. Alloys Compd. 728, 424. (2017).

30. Z. Sun, X. Tan, S.B. Tor, and C.K. Chua, NPG Asia Mater 10, 127. (2018).

31. S.-H. Sun, K. Hagihara, and T. Nakano, Mater. Des. 140, 307. (2018).

32. H.Y. Wan, Z.J. Zhou, C.P. Li, G.F. Chen, and G.P. Zhang, J. Mater. Sci. Technol. 34, 1799. (2018).

33. S.-H. Sun, T. Ishimoto, K. Hagihara, Y. Tsutsumi, T. Hanawa, and T. Nakano, Scr. Mater. 159, 89. (2019).

34. O. Andreau, I. Koutiri, P. Peyre, J.-D. Penot, N. Saintier, E. Pessard, T. De Terris, C. Dupuy, and T. Baudin, J. Mater. Process. Technol. 264, 21. (2019).

35. T. Ishimoto, S. Wu, Y. Ito, S.-H. Sun, H. Amano, and T. Nakano, ISIJ Int. 60, 1758. (2020).

36. M.S. Pham, B. Dovgyy, P.A. Hooper, C.M. Gourlay, and A. Piglione, Nat. Commun. 11, 749. (2020).

37. J.J. Marattukalam, D. Karlsson, V. Pacheco, P. Beran, U. Wiklund, U. Jansson, B. Hjorvarsson, and M. Sahlberg, Mater. Des. 193, 108852. (2020).

38. O. Gokcekaya, N. Hayashi, T. Ishimoto, K. Ueda, T. Narushima, and T. Nakano, Addi. Manuf. 36, 101624. (2020). 
39. K.A. Sofinowski, S. Raman, X. Wang, B. Gaskey, and M. Seita, Addi. Manuf. 38, 101809. (2021).

40. T. Ishimoto, K. Hagihara, K. Hisamoto, and T. Nakano, Addi. Manuf. 43, 102004. (2021).

41. O. Gokcekaya, T. Ishimoto, S. Hibino, J. Yasutomi, T. Narushima, and T. Nakano, Acta Mater. 212, 116876. (2020).

42. S.-H. Lee, K. Hagihara, and T. Nakano, Metall. Mater. Trans. 43, 1588. (2012).

43. K. Hagihara, T. Nakano, H. Maki, Y. Umakoshi, and M. Niinomi, Sci. Rep. 6, 20779. (2016).

44. K. Hagihara, T. Nakano, and K. Sasaki, Scripta Mater. 123, 149. (2016).

45. M. Tane, S. Akita, H. Nakajima, T. Nakano, K. Hagihara, Y. Umakoshi, and M. Niinomi, Acta Mater. 56, 2856. (2008).

46. S.-H. Lee, M. Todai, M. Tane, K. Hagihara, H. Nakajima, and T. Nakano, J. Mech. Beh. Biomed. Mater. 14, 48. (2012).

47. M. Tane, K. Hagihara, M. Ueda, T. Nakano, and Y. Okuda, Acta Mater. 102, 373. (2016).

48. T. Nakano, K. Hagihara, A.R. Ribeiro, Y. Fujiia, T. Todo, R. Fukushima, and L.A. Rocha, Wear 478-479, 203758. (2021).

49. Z. Mao, Z. He, D. Chen, W.Y. Cheung, and S.P. Wong, Solid State Com. 142, 329. (2007).

50. K. Hagihara, M. Okubo, M. Yamasaki, and T. Nakano, Corr. Sci. 109, 68. (2016).

51. C.J. Todaro, M.A. Easton, D. Qiu, M. Brandt, D.H. StJohn, and M. Qian, Addi. Manuf. 37, 101632. (2021).

52. D. Yuan, X. Sun, L. Sun, Z. Zhang, C. Guo, J. Wang, and F. Jiang, Mater. Sci. Eng. A. 813, 141177. (2021).

53. T.T. Roehling, R. Shi, S.A. Khairallah, J.D. Roehling, G.M. Guss, J.T. McKeown, and M.J. Matthews, Mater. Des. 195 , 109071. (2020).

54. Q. Tan, J. Zhang, N. Mo, Z. Fan, Y. Yin, M. Bermingham, Y. Liu, H. Huang, and M.-X. Zhang, Addi. Manuf. 32, 101034. (2020).

55. K. Hagihara, T. Nakano, M. Suzuki, T. Ishimoto, Suyalatu, and S.-H. Sun, J. Alloy. Compd. 696, 67 (2017).

56. K. Hagihara, T. Ishimoto, M. Suzuki, R. Ozasa, A. Matsugaki, P. Wang, and T. Nakano, Scr. Mater. 203, 114111. (2021).

57. R.W. Messler, Principles of Welding (Wiley, New York, 2008).

58. F.C. Liu, X. Lin, C.P. Huang, M.H. Song, G.L. Yang, J. Chen, and W.D. Huang, J. Alloys Compd. 509, 4505. (2011)

59. T. Ishimoto, J. Yasutomi, S. Sugimoto, and T. Nakano, J. Smart Proc. 7, 229. (2018).

60. A. Takase, T. Ishimoto, R. Suganuma, and T. Nakano, Addit. Manuf. 47, 102257. (2021).

61. A. Takase, T. Ishimoto, R. Suganuma, and T. Nakano, Scripta Mater. 201, 113953. (2021).

62. S.-H. Sun, K. Hagihara, T. Ishimoto, R. Suganuma, Y.-F. Xue, T. Nakano, Addit. Manuf. 47, 102329. (2021).

63. R. Huiskes, H. Weinans, and B. Van Rietbergen, Clin. Orthop. Relat. Res. 274, 124. (1992).

64. D. Kumar, G. Shankar, K.G. Prashanth, and S. Suwas, Mater. Sci. Eng. A 820, 141483. (2021).

65. J.J. Marattukalam, D. Karlsson, V. Pacheco, P. Beran, U. Wiklund, U. Jansson, B. Hjörvarsson, and M. Sahlberg, Mater. Des. 193, 108852. (2020).

66. R.R. Dehoff, M.M. Kirka, W.J. Sames, H. Bilheux, A.S Tremsin, L.E. Lowe, and S.S. Babu, Mater. Sci. Tech. 31, 931. (2015).

67. L. Thijs, M.L. Montero Sistiaga, R. Wauthle, Q. Xie, J.-P. Kruth, and J. Van Humbeeck, Acta Mater. 61, 4657 (2013)

68. C. Tan, K. Zhou, W. Ma, B. Attard, P. Zhang, and T. Kuang, Sci. Technol. Adv. Mater. 19, 370. (2018).

69. D. Wang, Z. Wang, K. Li, J. Ma, W. Liu, and Z. Shen, Mater. Des. 162, 384-393. (2019).

70. A.V. Müller, G. Schlick, R. Neu, C. Anstätt, T. Klimkait, J. Lee, B. Pascher, M. Schmitt, and C. Seidel, Nucl. Mater. Energy 19, 184. (2019).

71. M. Higashi and T. Ozaki, Mater. Des. 191, 108588. (2020).

72. J. Yang, X. Jin, H. Gao, D. Zhang, H. Chen, S. Zhang, and X. Li, Mater. Charact. 170, 110694. (2020).
73. Z. Xiong, P. Zhang, C. Tan, D. Dong, W. Ma, and K. Yu, Adv. Eng. Mater. 22, 1901352. (2020).

74. Z. Hu, Y. Zhao, K. Guan, Z. Wang, and Z. Ma, Addi. Manuf. 36, 101579. (2020).

75. O. Gokcekaya, T. Ishimoto, T. Todo, R. Suganuma, R. Fukushima, T. Narushima, and T. Nakano, Curr. Comput.Aided Drug Des. 11, 9. (2021).

76. T. Todo, T. Ishimoto, O. Gokcekaya, J. Oh, and T. Nakano, Scr. Mater. 206, 114252. (2022).

77. D. Grossin, A. Monton, P. Navarrete-Segado, E. Özmen, G. Urruth, F. Maury, D. Maury, C. Frances, M. Tourbin, P. Lenormand, and G. Bertrand, Open Ceram. 5, 100073. (2021).

78. Z. Fan, M. Lu, and H. Huang, Ceram. Int. 44, 9484. (2018).

79. S. Song, Z. Gao, B. Lu, C. Bao, B. Zheng, and L. Wang, Ceram. Int. 46, 568. (2020).

80. J. Wilkes, Y. Hagedorn, W. Meiners, and K. Wissenbach, Rapid Prototyp. J. 19, 51. (2013).

81. C. Shuai, C. Gao, Y. Nie, H. Hu, Y. Zhou, and S. Peng, Nanotechnology 22, 285703. (2011).

82. A. Aramian, Z. Sadeghian, D. Wan, Y. Holovenko, S.M.J. Razavi, and F. Berto, Mater. Charact. 178, 111289. (2021).

83. K. Ito, H. Inui, Y. Shirai, and M. Yamaguchi, Philos. Mag. A 72, 1075. (1995)

84. K. Ito, T. Yano, T. Nakamoto, M. Moriwaki, H. Inui, and M. Yamaguchi, Prog. Mater. Sci. 42, 193. (1997).

85. T. Nakano, K. Hagihara, Y. Nakai, and Y. Umakoshi, Intermetallics 14, 1345. (2006).

86. K. Hagihara, H. Araki, T. Ikenishi, and T. Nakano, Acta Mater. 107, 196. (2016).

87. M. Esmaily, Z. Zeng, A.N. Mortazavi, A. Gullino, S Choudhary, T. Derra, F. Benn, F. D'Elia, M. Müther, S. Thomas, A. Huang, A. Allanore, A. Kopp, and N. Birbilis, Addit. Manuf. 35, 101321. (2020).

88. N. Ikeo, T. Ishimoto, A. Serizawa, and T. Nakano, Metal. Mater. Trans. A 45, 4293. (2014).

89. M. Neikter, R. Woracek, T. Maimaitiyili, C. Scheffzük, M Strobl, M.-L. Antti, P. Ảkerfeldt, R. Pederson, and C. Bjerkén, Addit. Manuf. 23, 225. (2018).

90. A.I. Saville, S.C. Vogel, A. Creuziger, J.T. Benzing, A.L. Pilchak, P. Nandwana, J. Klemm-Toole, K.D. Clarke, S.L. Semiatine, and A.J. Clarke, Addit. Manuf. 46, 102118. (2021).

91. S. Milton, O. Rigo, S. LeCorre, A. Morandeau, R. Siriki, P. Bocher, and R. Leroy, Mater. Sci. Eng. A 823, 141773. (2021).

92. Y. Zhang, Z. Chen, S. Qu, A. Feng, G. Mi, J. Shen, X. Huang, and D. Chen, J. Mater. Sci. Tech. 70, 113. (2021).

93. M. Todai, T. Nakano, T. Liu, H.Y. Yasuda, K. Hagihara, K. Cho, M. Ueda, and M. Takayama, Addi. Manuf. 13, 61. (2017).

94. M. Seifi, A.A. Salem, D. Satko, U. Ackelid, S.L. Semiatin, and J.J. Lewandowski, J. Alloys Compd. 729, 1118. (2017).

95. Y. Chen, H. Yue, and X. Wang, Mater. Sci. Eng. A 713, 195. (2018).

96. K. Cho, R. Kobayashi, J.Y. Oh, H.Y. Yasuda, M. Todai, T. Nakano, A. Ikeda, M. Ueda, and M. Takeyama, Intermetallics 95, 1. (2018).

97. Y.-K. Kim, S.-J. Youn, S.-W. Kim, J. Hong, and K.-A. Lee, Mater. Sci. Eng. A 763, 138138. (2019).

98. K. Cho, H. Kawabata, T. Hayashi, H.Y. Yasuda, H. Nakashima, M. Takeyama, and T. Nakano, Addi. Manuf. 46, 102091. (2021)

99. P. Li, Y. Zhang, W. Y. Wang, Y. He, J. Wang, M. Han, J. Wang, L. Zhang, R. Zhao, H. Kou, M. Qian, and J. Li, Mater. Sci. Eng. A 824, 141815. (2021).

Publisher's Note Springer Nature remains neutral with regard to jurisdictional claims in published maps and institutional affiliations. 